\title{
El castellano del País Vasco
}

Ed. by Bruno Camus Bergareche \& Sara Gómez Seibane

Bilbao: Universidad del País Vasco, 280 pages.

ISBN: 978-84-9860-767-3

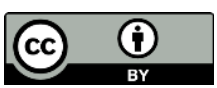

Received: 08-02-19

Accepted: 19-02-2019

Reviewed by Laura Arias Rodríguez

Universitat Autònoma de Barcelona

The volume under review is the first book aiming to describe the variety of Spanish in contact with Basque. Offering a wide characterisation of the variety, the volume is structured in four sections: bilingualism and language contact, lexicon, phonetics and syntax, each containing at least two chapters. The editors, Bruno Camus and Sara Gómez Seibane, open the volume with a comprehensive introduction, which presents some historical and social facts about the variety and delimits it geographically.

Due to its descriptive nature, this volume will be accessible for non-specialist readers seeking examples of language contact phenomena as well as readers interested in a detailed overview of the Spanish of the Basque Country. The volume contains a wealth of data, including experimental research and examples from corpora.

In his chapter, Jorge Etxague begins the section on bilingualism and language contact by describing the variety of Basque Country Spanish in the literature of the $16^{\text {th }}$ century and $17^{\text {th }}$ century. This so-called Vizcaino speech had a stereotypical and humorous intention, but some of the specific properties shown in the literature may be due to the interference of Basque. The analysis of literary works is complemented with a sociolinguistic background of the Basque Country in the $17^{\text {th }}$ century.

In their chapter, Orreaga Ibarra Murillo offers a description -with a focus on the lexicon- of the Spanish spoken by young Basque bilinguals from urban and rural areas, using data from questionnaires and a survey of the literature. The author argues that both Basque and Spanish are undergoing a process of dialect levelling as a result of education, mass media and other social factors. Finally, a brief analysis of code-switching is provided, and the author arrives at the conclusion that this phenomenon has an identity function and obeys certain restrictions. 
Maitena Etxebarria analyses lexical availability in Spanish amongst schoolchildren from the Basque Country. She discusses the sociolinguistic backdrop and provides a description of the educational system in the Basque Country, particularly the different models of bilingual education. Her study compares the lexical knowledge of students from two different bilingual models, and concludes that no significant difference is found between these groups. In a similar vein, there is no difference in relation to monolingual speakers from Spain.

Isabel Echevarría investigates Basque toponymy based on an in-depth examination of the literature. Toponymy reflects historical changes and is relevant to the study of dialects within the Basque territory. Crucially, the toponymy of the Basque Country shows that the influence of Romance has been historically unequal across different areas.

In their chapter, Gorka Elordieta and Aritz Irurtzun examine tonal alignment in stressed vowels in the Spanish of Bilbao. As a continuation of previous work, the authors compare the intonation of speakers from Bilbao when reading sentences to the intonation of speakers from Lekeitio, from Vitoria-Gasteiz and from Madrid. The study finds that the patterns of this dialect are different from those of Lekeitio Spanish and Madrid Spanish, being more similar to the patterns of Vitoria Spanish.

Miren Lourdes Oñederra deals with yeísmo, that is, the loss of the palatal lateral phoneme $/ K /$ in favour of the palatal central phoneme $/ J /$. Lourdes Oñederra explains that this is a process of delateralization of the palatal sonant and argues that it has not been accomplished in the Spanish of the Basque Country, especially amongst bilingual speakers. She conducts a limited empirical study with twelve informants -both bilinguals and monolinguals- but no significant findings are obtained.

Jon Ander Merino focuses on trills /r/ and flaps / $/$ / in the Spanish spoken in Bizkaia, since a trill instead of a tap can be produced in certain contexts. His empirical study finds that the production of one phoneme instead of the other is significantly more likely in the case of speakers with a greater exposure to Basque, while other variants such as age, sex or region, do not play a determining role.

Carmen Isasi Martínez, Alexander Iribar and Itziar Aguirrezabal conclude the section on phonetics with their study of seseo in the Spanish of the Basque Country. A documentary study and an analysis of oral data indicate that seseo is a specific development of the area of Spanish-Basque contact that is disappearing nowadays. The authors also study the phonetic realisation of the sibilant, and they find a different manifestation if the speaker has the apical /predorsodental distinction in Basque.

Sara Gómez Seibane studies the omission of the direct object and the doubling of both direct and indirect objects in the Basque Country Spanish as well as in other variants of Spanish in contact. Her analysis is based on hierarchies of animacy and definiteness. Based on a corpus analysis, she proposes that null objects and object doubling have changed in terms of their sensitivity to animacy and definiteness.

Bruno Camus explores the syntactic strategies by which Basque Country Spanish expresses mood, evidentiality and modality. Particularly, by discussing 
data from corpora, he studies some expressions and words in Standard Spanish that have a different meaning in the Basque Country Spanish, such as soler + infinitive or the adverb $y a$.

Finally, José Luis Ramírez analyses the substitution of the past subjunctive (i.e. cantara/ cantase "sang") for conditional (i.e. cantaria "would sing") in the Basque Country Spanish and other dialects. He provides an overview of the distribution of this phenomenon, its history and a review of the literature on this topic.

El castellano del País Vasco constitutes, in sum, the only complete description of the Basque Country Spanish. Offering a diachronic and synchronic perspective, it is written in an informative tone and includes a great volume of data to illustrate the variety in question. However, the work lacks a theoretical approach and further research is needed on most of the issues discussed. Surprisingly, none of the chapters include a theoretical discussion on language contact phenomena. All in all, the volume is a step forwards in the study of dialectal variation in Spanish. 